\title{
Effects of Gamma Radiation on the Composition of the Hydrocarbon Mixture Hexane-hexene
}

\author{
Ramin Akberov, Lala Jabbarova, Islam Mustafayev, Sevinc Melikova \\ Institute of Radiation Problems, National Academy of Sciences of Azerbaijan, Baku, Azerbaijan
}

Email address:

ramin_r_g@mail.ru (R. Akberov)

\section{To cite this article:}

Ramin Akberov, Lala Jabbarova, Islam Mustafayev, Sevinc Melikova. Effects of Gamma Radiation on the Composition of the Hydrocarbon Mixture Hexane-hexene. Radiation Science and Technology. Special Issue: Radiolysis of Hexane-Hexene Hydrocarbon Mixture.

Vol. 6, No. 2, 2020, pp. 12-18. doi: 10.11648/j.rst.20200602.11

Received: October 29, 2019; Accepted: January 17, 2020; Published: June 28, 2020

\begin{abstract}
In work the impact of ionizing radiation on mixes hexane- hexene was investigated. Laboratory researches were conducted on a gamma source ${ }^{60} \mathrm{Co}$ at the power of dose of $\mathrm{P}=0.10$ of $\mathrm{Gy} / \mathrm{s}$ in intervals of the absorbed doses $\mathrm{D}=34-103 \mathrm{kGy}$. Impact of ionizing radiation on structural and group composition of mix hexane- hexene in static conditions was investigated. Density, viscosity, iodic numbers of mixes hexane- hexene were determined. before radiation at various absorbed doses. Existence of olefin connections is the main reason for small stability in hydrocarbon fuels. Studying of radiolysis of mixes of saturated and nonsaturated hydrocarbons at various concentration gives the chance to draw conclusions about the nature of the main radiochemical processes. In the fuels containing a large amount of nonsaturated hydrocarbons in the course of radiation the coking behavior increases and color worsens. Structuring is physically shown in organic liquids in change of viscosity and density. The processes which arose in connection with radiolysis for a long time develop after the radiation termination that can lead to change of composition of fuel. As a result of it at ambient temperature operational properties of oil fuels worsen. Communication between the chemical composition of fuel and its stability is still insufficiently well studied. These experiments continue for the purpose of studying of impact of ionizing radiation on changes of physical and chemical properties of hydrocarbons of oil.
\end{abstract}

Keywords: Radiolysis, Iodic Numbers, Hexane, Hexene

\section{Introduction}

The main reason of hydrocarbon fuels low stability is the presence of olefinic compounds. The study of the radiolysis of saturated and unsaturated hydrocarbons mixtures at various concentrations makes it possible to draw conclusions about the nature of the main radiation-chemical processes. In fuels containing a large amount of unsaturated hydrocarbons, in the irradiation process, coking behavior increases and color deteriorates. The processes that have arisen in connection with radiolysis continue for a long time after the cessation of irradiation, which can lead to a change in the composition of the fuel. Structuring is physically manifested in organic liquids in changes of viscosity and density. The amount of decomposed hydrocarbon increases with increasing total radiation dose. As a result, at ambient temperature, the performance properties of petroleum fuels deteriorate. The relationship between the chemical composition of the fuel and its stability is not well understood. These experiments continue to study the effect of ionizing radiation on changes in the physico-chemical properties of petroleum hydrocarbons. We studied several operational performance of fuel under static conditions in the usual manner before and after irradiation. The results of the experimental studies on radiation resistance of various oil products have been previously conducted in the papers [111]. In connection with the opportunity to develop new technological processes with the use of radioactive energy, it is necessary to study the effect of various types of radiation on hydrocarbons and oil products. Stability is understood as the ability of a fuel to maintain its chemical structure under operating conditions with a change in temperature, ionizing radiation and under the influence of metals. It is necessary to provide a radiation resistance in the physical and chemical properties of the fuel. 


\section{Methodology}

The samples (hexane-hexene mixture $\mathrm{ml}$ ) placed in ampoules and sealed in vacuum, were irradiated at room temperature on gamma-source $\mathrm{Co}^{60}$ at dose rate $\mathrm{P}=0,18 \mathrm{~Gy} / \mathrm{h}$ at different absorption doses: within the range of $15-150 \mathrm{kGy}$ in vacuum so as to trace the kinetics of the current processes. As an ionizing radiation it was used Y-radiation source $\mathrm{Co}^{60}$ of type MPX Y-30.

IR-absorption spectra of the studied samples were registered on spectrometer VARIAN 640-IR (VARIAN Company) in the wavelength range $\left(4000-400 \mathrm{~cm}^{-1}\right)$. The samples were removed in the form of film with a thickness of $\mathrm{d}=1$. Distribution of bands of the obtained spectra was carried out as described in Tarasevich 's handbook. Gas products were analyzed by gas chromatography method. The density was determined by a pycnometer according to GOST 390085 . The viscosity was determined according to GOST 33-66 by a viscometer of VPJ-2 type corresponding to GOST 10028-81. The aim of the work is the study of radiation resistance of hexane-hexene mixtures were determined before and after irradiation at various absorbed doses.

\section{Experiments and Results}

Structuring physically manifests itself in organic fluids in changes in viscosity and density. The effect of gamma radiation on the density and viscosity of the hexane-hexene mixture at various concentrations $(\%)$ and ranges of absorbed doses is shown in Figure $1(a, b)$.

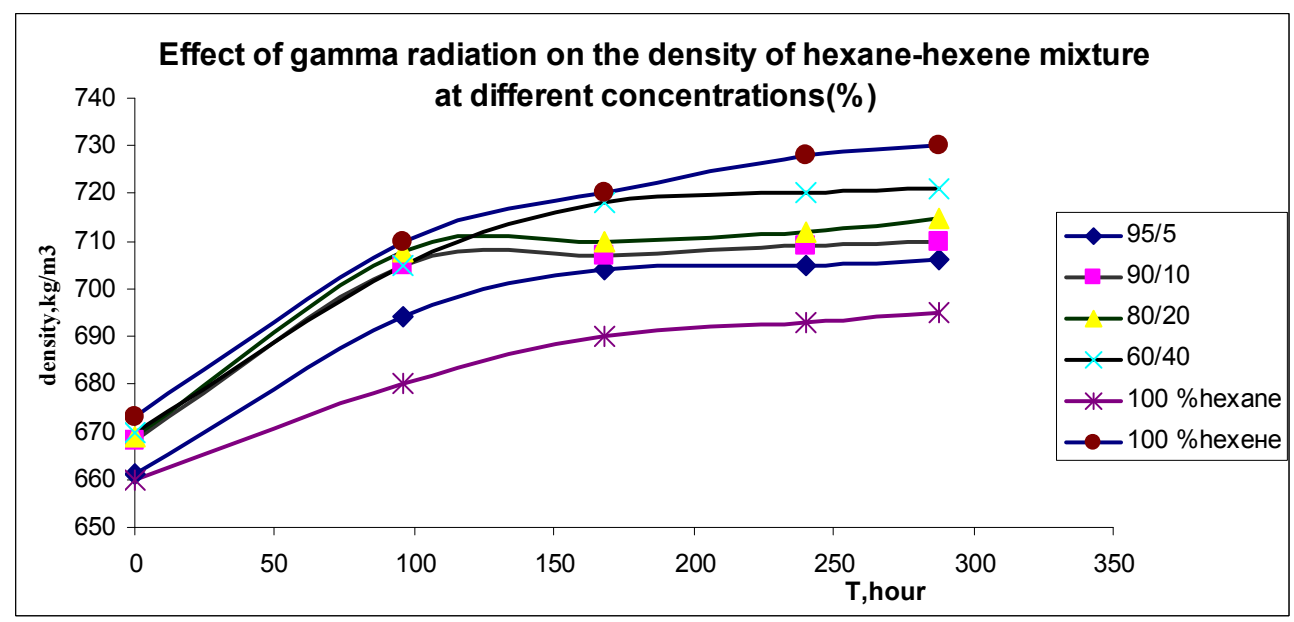

a

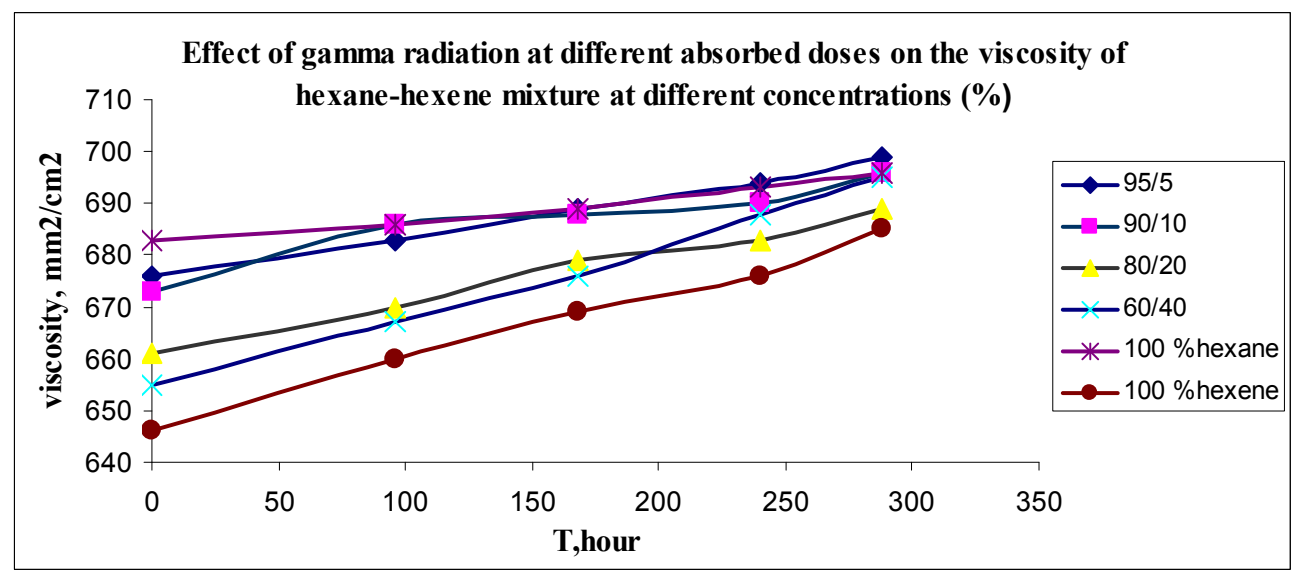

b

Figure 1. (a, b). The effect of gamma radiation on the density and viscosity of the hexane-hexene mixture at different concentrations (\%) at different absorbed doses.

The viscosity varies the greater the absorbed dose of ionizing radiation. If the viscosity exceeds the permissible limits, the operation of the fuel supply equipment will be impaired. The density indirectly characterizes the chemical properties of the fuel, fractional composition and vaporability.

Chemical method is used together with IR spectroscopy while determining the uncertainties. The results of IR spectroscopic studies of the hexane-hexene mixture are shown in Figure 2 (a, b, c, d, e, i, k, 1, m, n) 


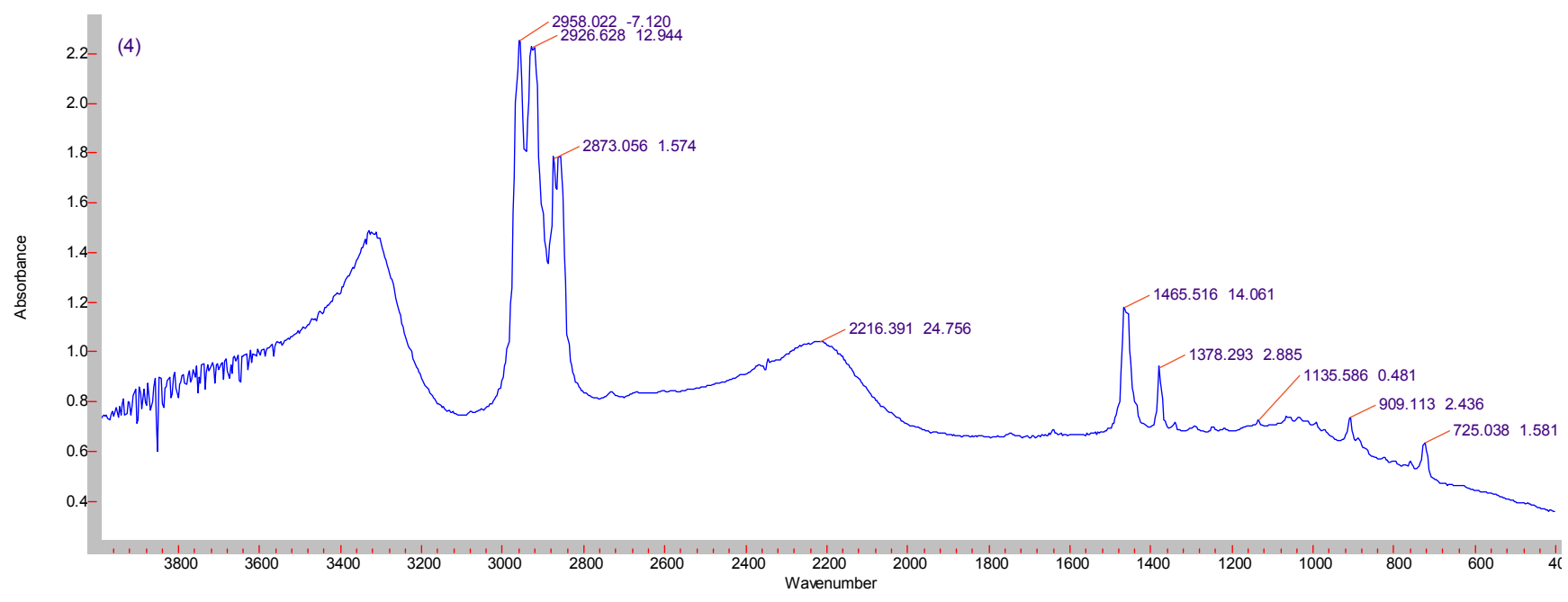

a. Unirradiated mixture ( $95 \% \mathrm{n}$-hexane $5 \%$ hexene).

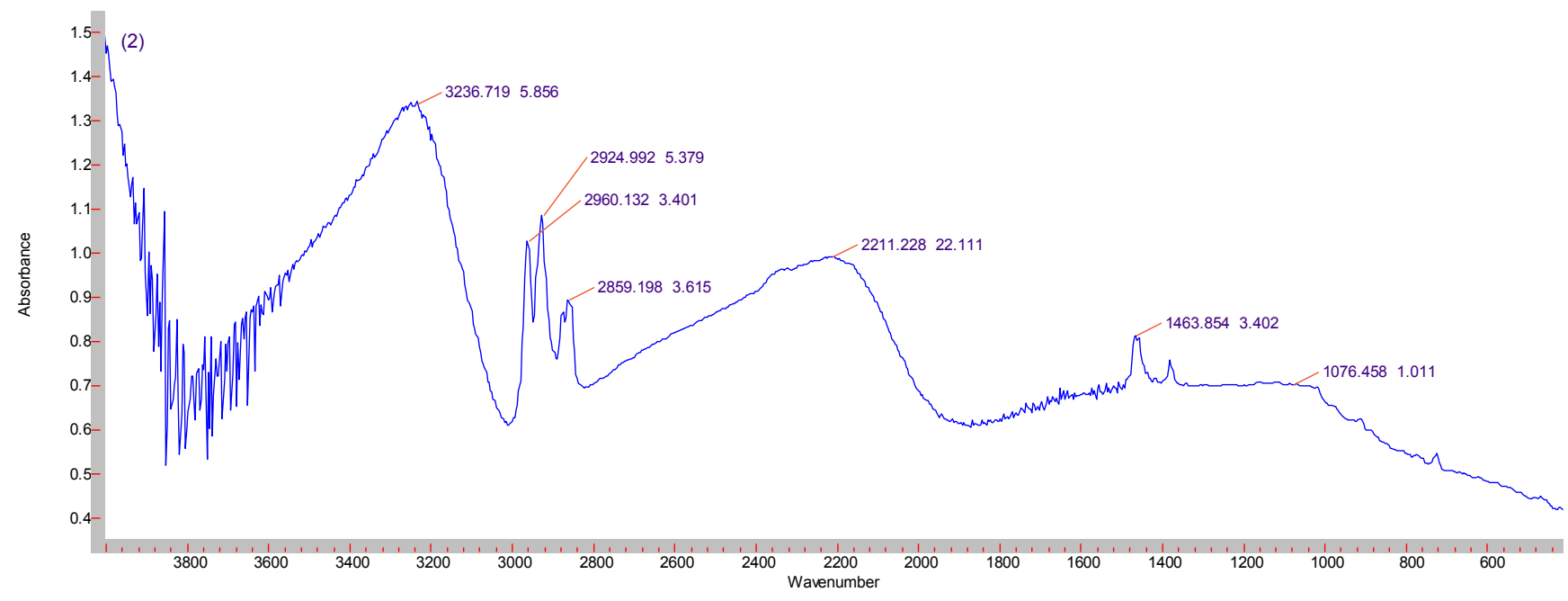

b. Irradiated 96 hours ( $95 \%$ n-hexane 5\% hexene).

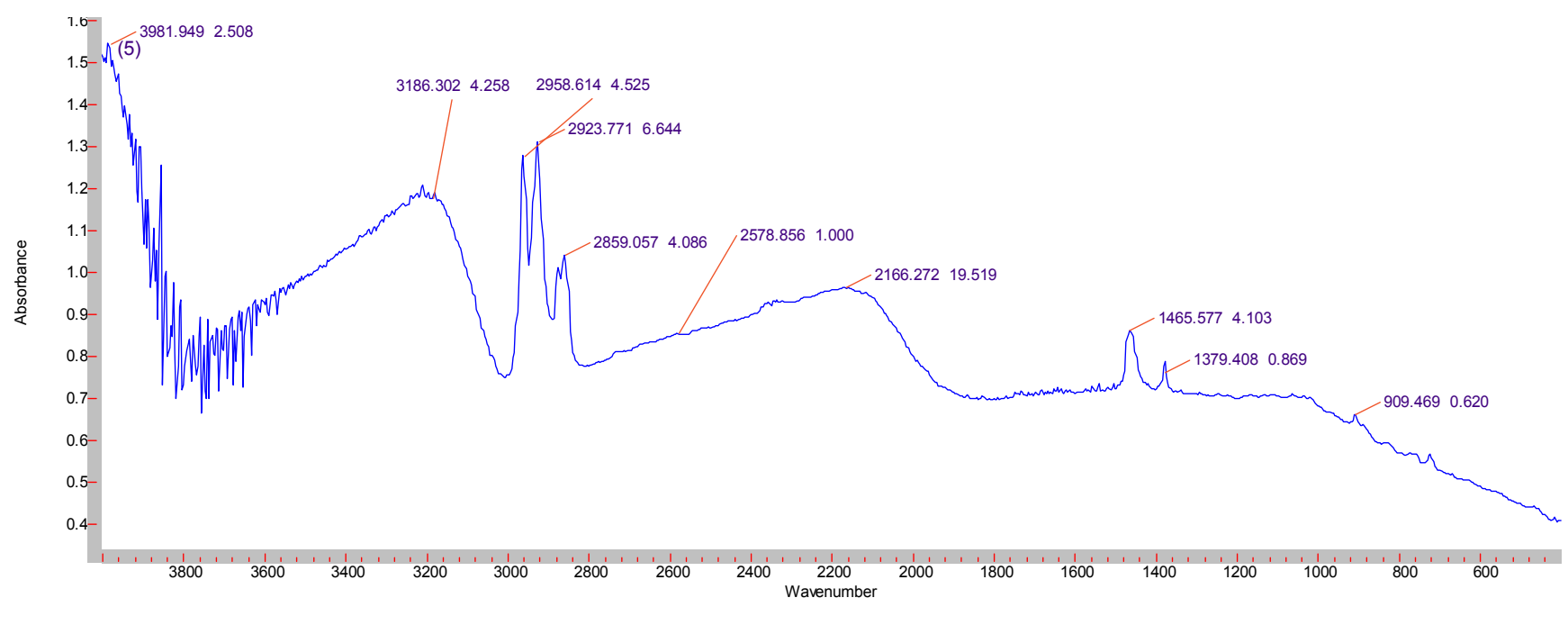

c. Irradiated 288 hours (95\% n-hexane 5\% hexene). 


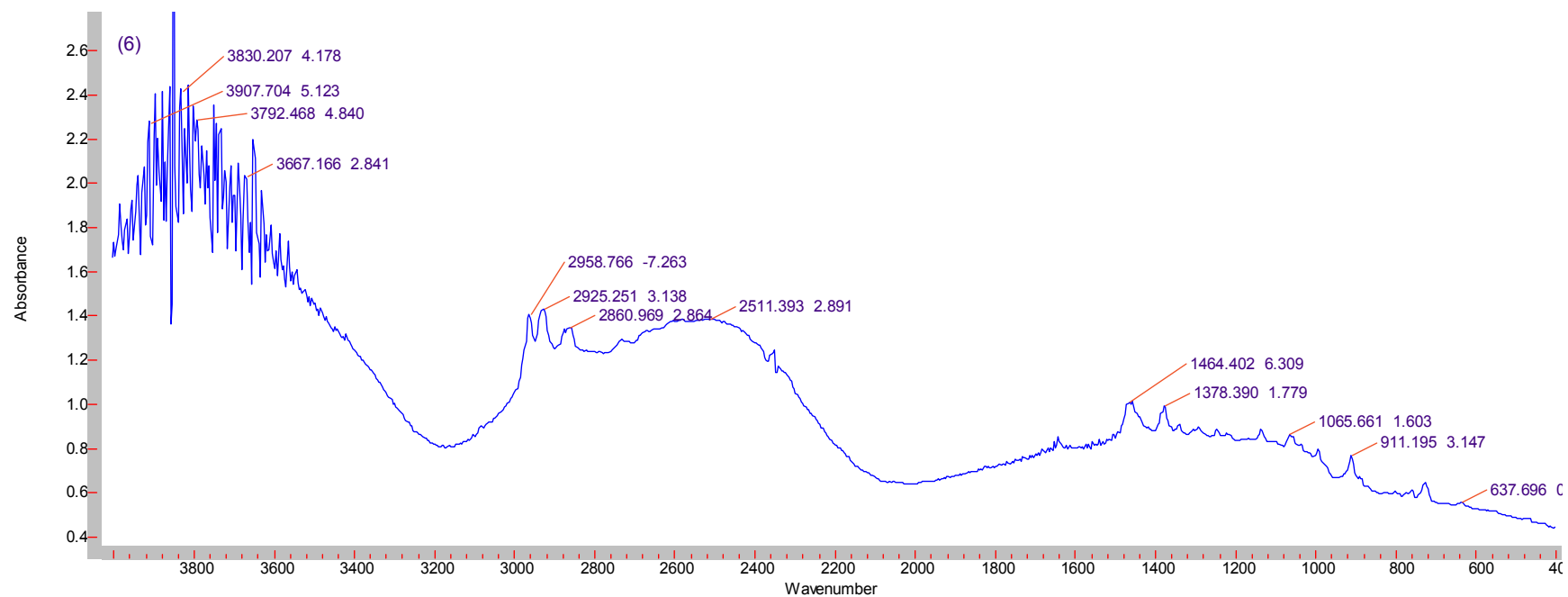

d. Unirradiated mixture (10\%) (90\% n-hexane 10\% hexene).

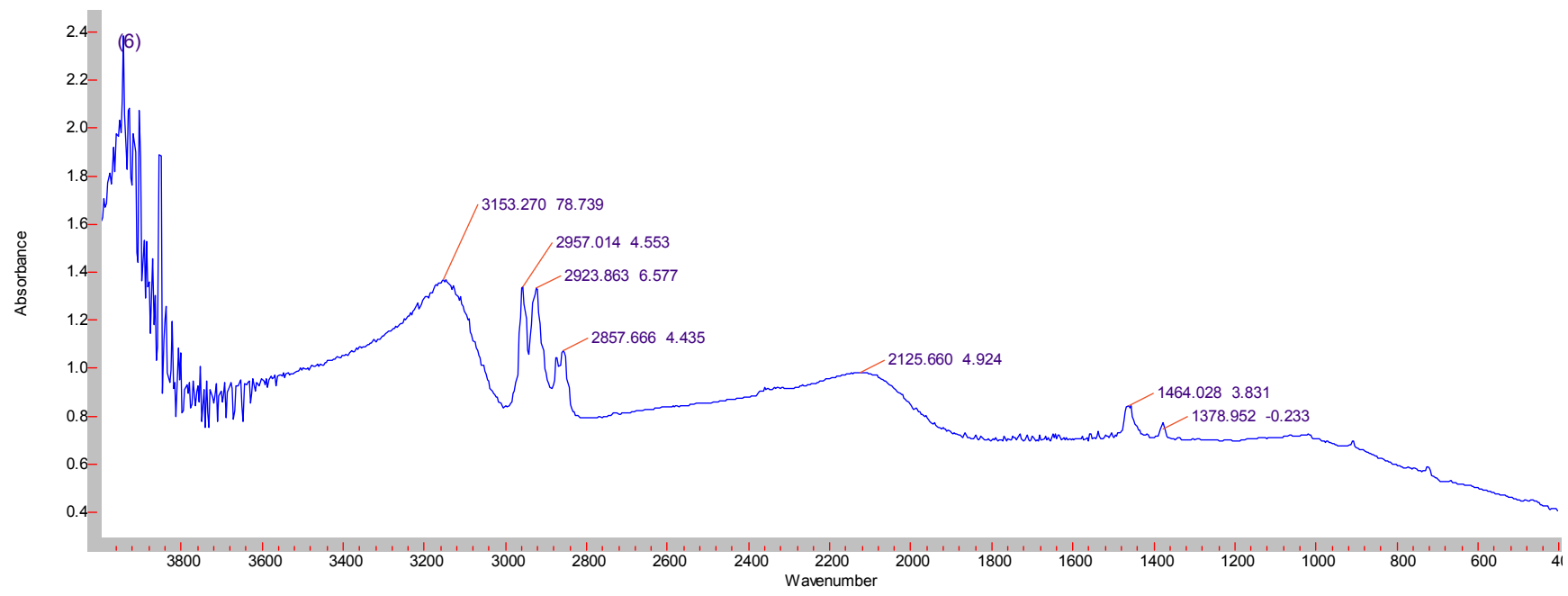

e. Irradiated 96 hours ( $90 \%$ n-hexane $+10 \%$ hexene) .

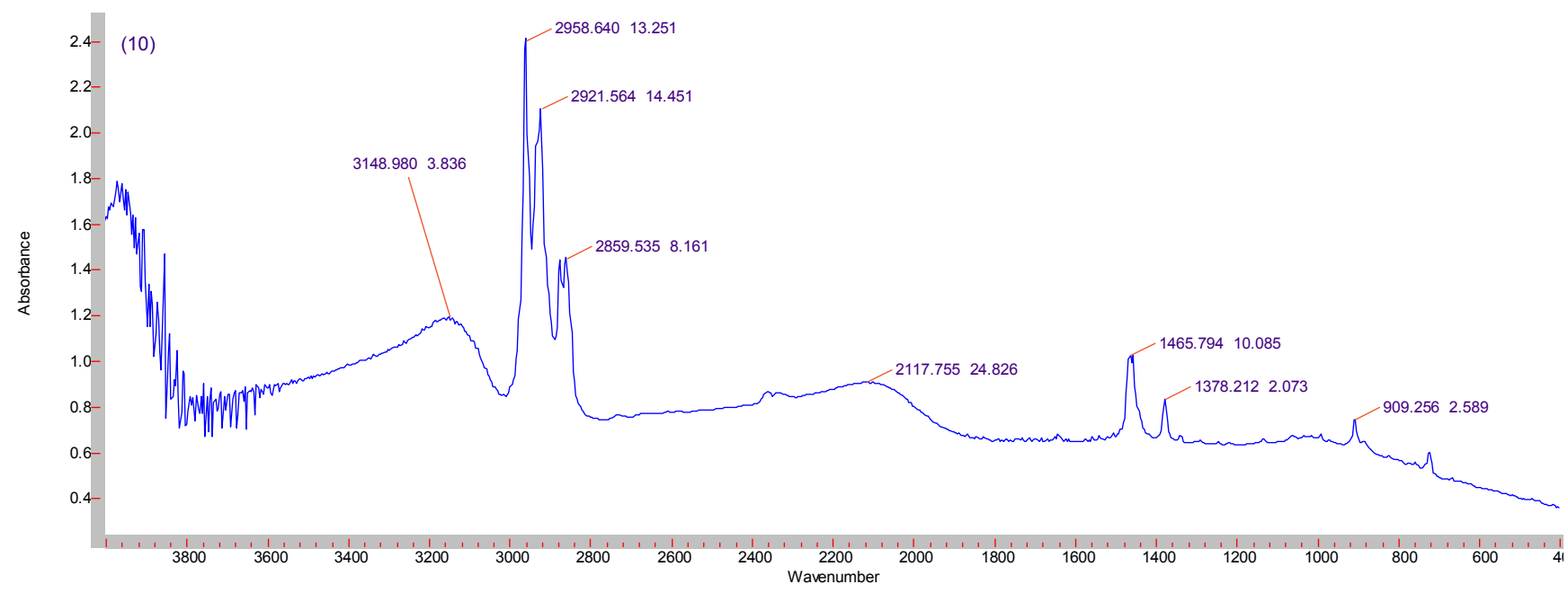

i. Irradiated 288 hours $(90 \%$ n-hexane $+10 \%$ hexene). 


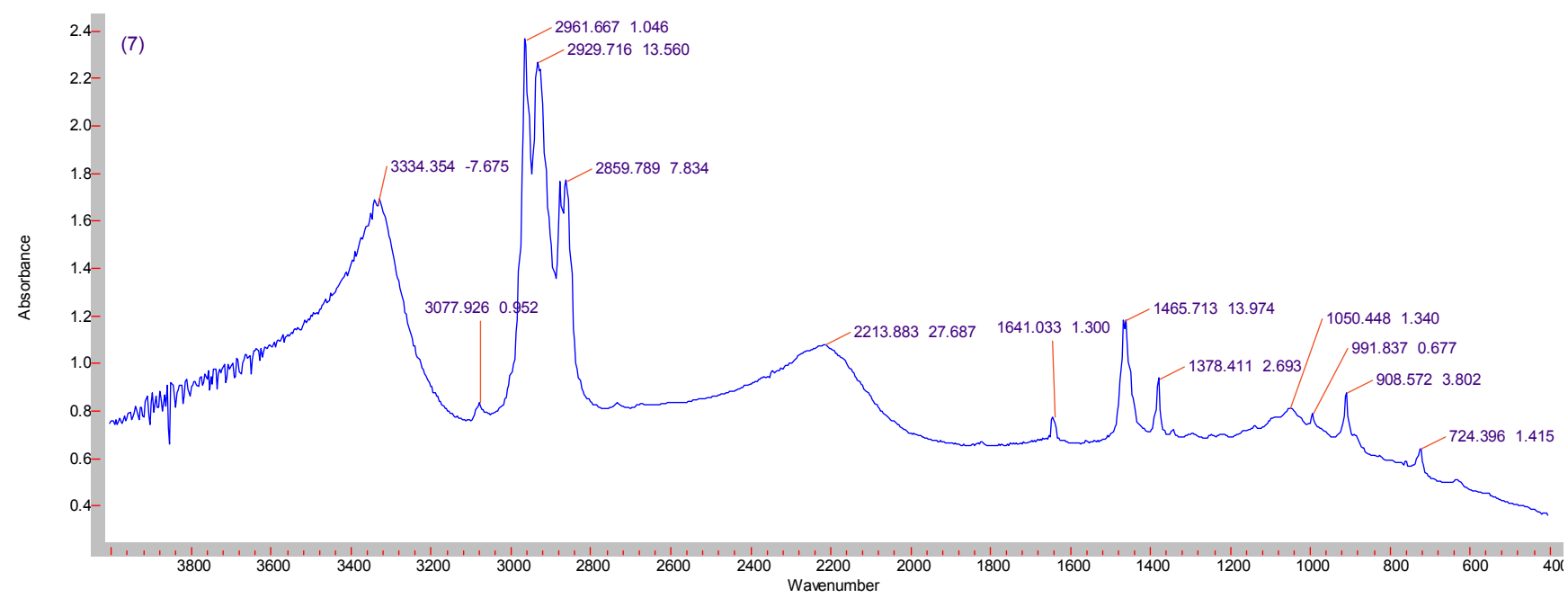

k. Unirradiated mixture ( $80 \%$ n-hexane $+20 \%$ hexene).

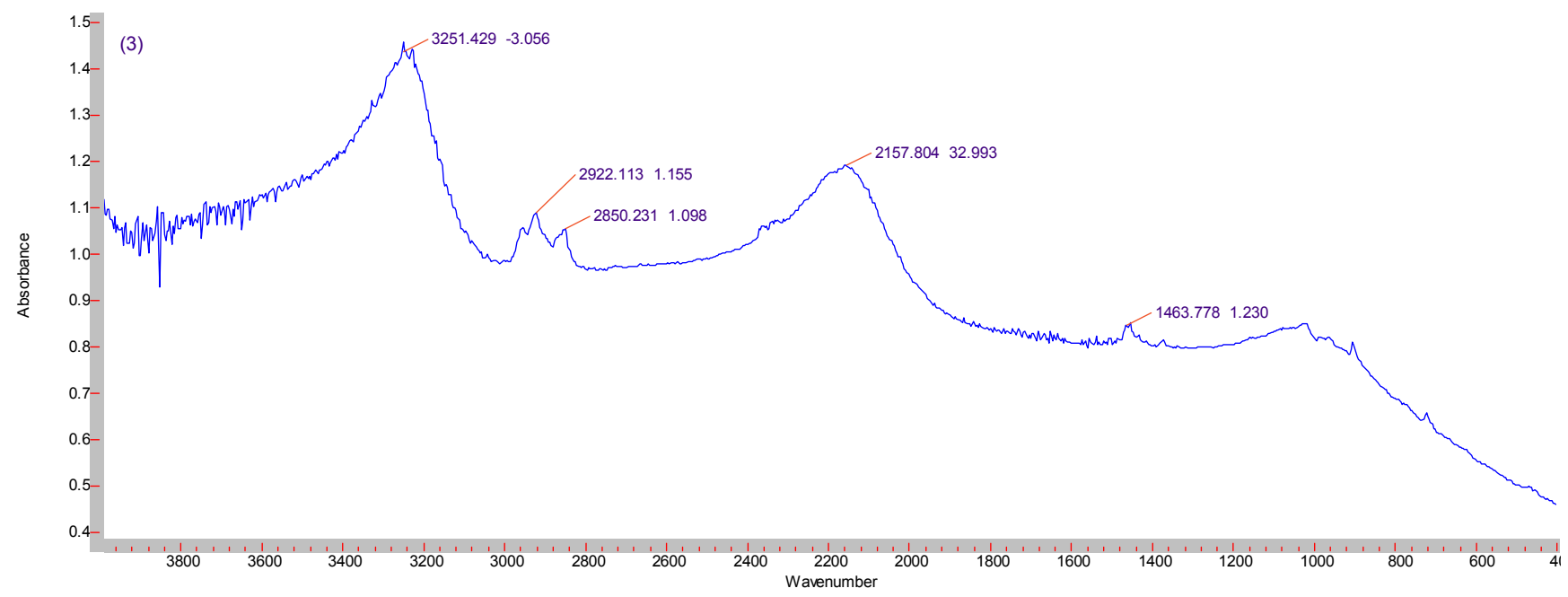

1. Irradiated 288 hours. $(80 \%$ n-hexane $+20 \%$ hexene) .

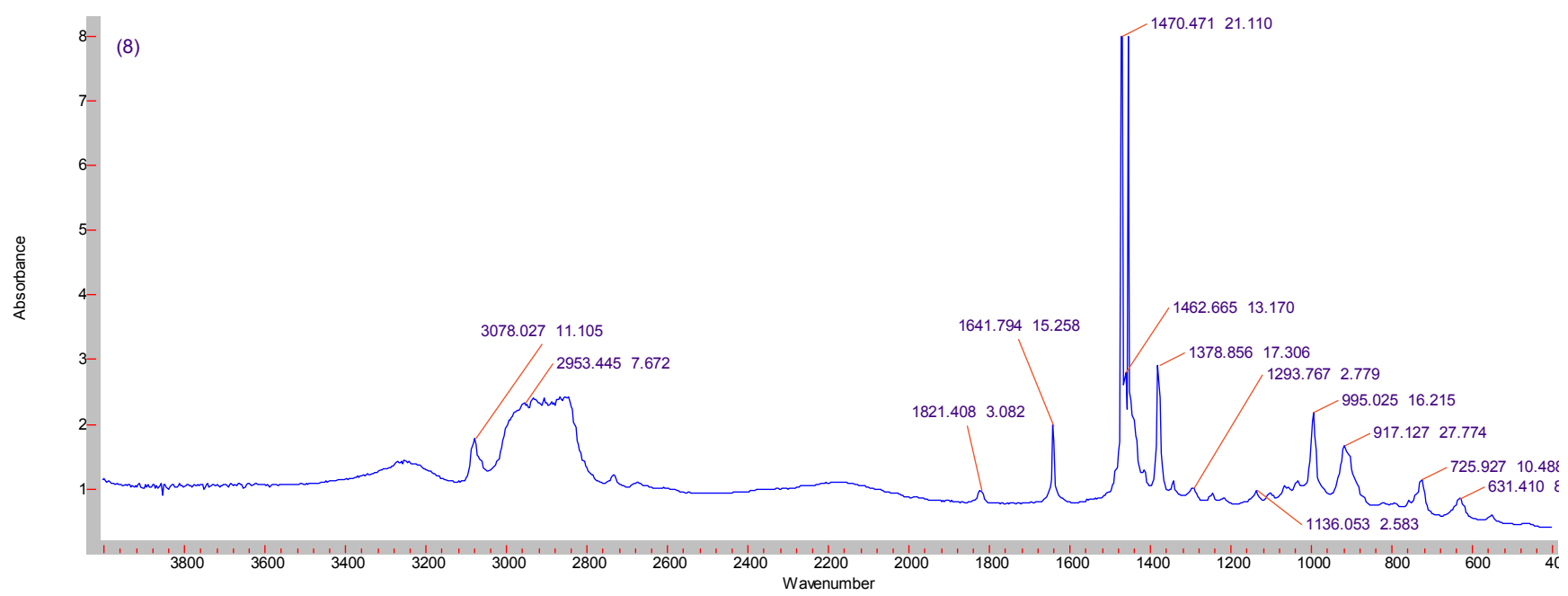

m. Unirradiated mixture ( $60 \% \mathrm{n}$-hexane $+40 \%$ hexene) . 


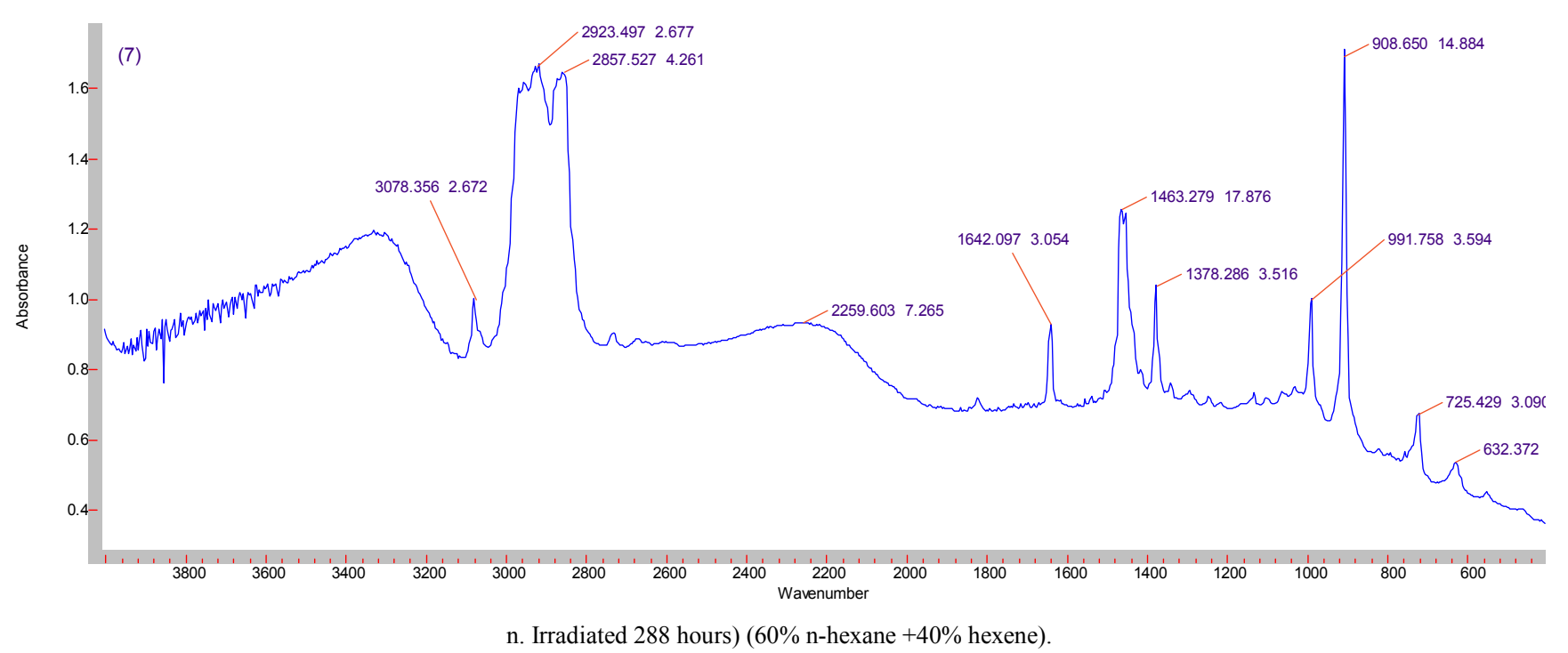

Figure 2. $(a, b, c, d, e, i, k, l, m, n)$. Results of IR spectroscopic studies of hexane-hexene mixture before and after irradiation at different absorbed doses.

Unirradiated mixture $(95 \%$ n-hexane $5 \%$ hexene) Out-ofplane deformation oscillations of group $\mathrm{C}-\mathrm{H}$ in the area of $1000-650 \mathrm{~cm}^{-1}$. Plane deformation oscillations of $\mathrm{C}-\mathrm{H}$ group in the area of 1225-950 $\mathrm{cm}^{-1}, 2880-2650$-absorption band $\mathrm{C}=\mathrm{O}$ in aldehyde groups. (1380-1370) $\mathrm{cm}^{-1}$-deformation oscillations $-\mathrm{CH}_{3}$ gr. $1465-1440 \mathrm{sm}^{-1}-(2975-2950) \mathrm{cm}^{-1}-$ fluctuations of S-H bonds in alkanes

After irradiated 288 hours mixture (95\% n-hexane 5\% hexene) Out-of-plane deformation oscillations of group C-H in the area of $1000-650 \mathrm{~cm}^{-1},(1380-1370) \mathrm{cm}^{-1}$-deformation oscillations $\mathrm{CH}_{3}$ g. (1465-1440) $\mathrm{cm}^{-1}$ (2940-2915), (2975-2950) $\mathrm{cm}^{-1}$ fluctuations of $\mathrm{C}-\mathrm{H}$ bonds in alkanes, 2240-2200 cm-1absorption in alkynes. 3220-3180 cm-1-valence oscillations N-H, (2860-2960) cm-1 - valence oscillations of $\mathrm{CH}_{3}$.

Unirradiated mixture (10\%) (90\% n-hexane 10\% hexene) Plane deformation vibrations $\mathrm{C}-\mathrm{H}$ are observed in the region (1225-950) cm $\mathrm{cm}^{-1}$. (1370-1380, 1465-1440, 2975-2950, 2880$2650 \mathrm{~cm}^{-1}$ - deformation vibrations $-\mathrm{CH}_{3}-\mathrm{g}, 1470-1435 \mathrm{~cm}^{-1}$ vibration of bond $-\mathrm{CH}_{3}$. $2975-2950 \mathrm{~cm}^{-1}$ vibration of $\mathrm{CH}_{3}$ bonds in alkenes.

After irradiated (288 hour) ( $90 \%$ n-hexane $+10 \%$ hexene) Plane deformation vibrations $\mathrm{C}-\mathrm{H}$ are observed in the region (1225-950) $\mathrm{cm}^{-1}$. (1370-1380) $\mathrm{cm}^{-1}$ - deformation vibrations $\mathrm{CH}_{3}-\mathrm{g}, 1470-1435 \mathrm{~cm}^{-1}$ vibration of bond $-\mathrm{CH}_{3} .2975-2950$ $\mathrm{cm}^{-1}$ vibration of $\mathrm{CH}_{3}$ bonds in alkenes, 3130-3030 $\mathrm{cm}^{-1}$ deformation vibration of $\mathrm{N}-\mathrm{H}$ group of amino acid.

Unirradiated mixture ( $80 \%$ n-hexane $+20 \%$ hexene) Out-ofplane deformation oscillations of group $\mathrm{C}-\mathrm{H}$ in the area 1000-650 $\mathrm{cm}^{-1}$. (1380-1370) $\mathrm{cm}^{-1}$-deformation oscillations $-\mathrm{CH}_{3} \cdot 1465$ $1440 \mathrm{sm}^{-1}-(2975-2950) \mathrm{cm}^{-1}-$ fluctuations of S-H bonds in alkanes.

After irradiated 288 hours mixture $(80 \%$ n-hexane $20 \%$ hexene) 1465-1440) $\mathrm{cm}-1$-connection of $\mathrm{C}-\mathrm{H}$ bonds in alkanes, 2160-2120 cm-1-cumulated double bonds, (28602960) cm-1 - valence oscillations of $\mathrm{CH}_{3}$. (2940-2915), (2975-2950) cm-1- fluctuations of S-N connections in alkanes, 3220-3180 cm-1-valence oscillations N-H

Unirradiated mixture (60\% n-hexane $+40 \%$ hexene) Plane deformation vibrations $\mathrm{C}-\mathrm{H}$ are observed in the region (1225-
950) $\mathrm{cm}^{-1}$. (1370-1380) $\mathrm{cm}^{-1}$ - deformation vibrations $-\mathrm{CH}_{3}-\mathrm{g}$, $1470-1435 \mathrm{~cm}^{-1}$ vibration of bond $-\mathrm{CH}_{3}-, 1606-\mathrm{cm}^{-1} \mathrm{C}=\mathrm{C}$ valence vibration of aromatic ring, $1645-1640 \mathrm{~cm}-1$-valent bond fluctuations $\mathrm{C}=\mathrm{C}$ in alkenes, 1800-1850- cm-1deformation oscillations of $\mathrm{C}-\mathrm{H}$ bonds in alkenes and types of substitution in case of double bonds. 2975-2950 $\mathrm{cm}^{-1}$ vibration of $\mathrm{CH}_{3}$ bonds in alkenes, 3130-3030 $\mathrm{cm}^{-1}$ deformation vibration of $\mathrm{NH}_{2}$ group of amino acid.

After irradiated 288 hours mixture $(60 \%$ n-hexane $40 \%$ hexene) Plane deformation vibrations $\mathrm{C}-\mathrm{H}$ are observed in the region (1225-950) $\mathrm{cm}^{-1}$. (1370-1380) $\mathrm{cm}^{-1}$ - deformation vibrations $-\mathrm{CH}_{3}-\mathrm{g}, 1470-1435 \mathrm{~cm}^{-1}$ vibration of bond $-\mathrm{CH}_{3}-$, $1606-\mathrm{cm}^{-1} \mathrm{C}=\mathrm{C}$ valence vibration of aromatic ring, $1645-1640$ $\mathrm{cm}-1$-valent bond fluctuations $\mathrm{C}=\mathrm{C}$ in alkenes. $2140-2080 \mathrm{~cm}^{-}$ ${ }^{1}$ vibrations of $\mathrm{CO}_{2}$ groups, $2940-2915 \mathrm{~cm}^{-1}$ vibration of $\mathrm{CH}_{2}$ bonds in alkenes, 2275-2260-cumulated double bonds. 2975$2950 \mathrm{~cm}^{-1}$ vibration of $\mathrm{CH}_{3}$ bonds in alkenes, $3130-3030 \mathrm{~cm}^{-1}$ deformation vibration of $\mathrm{NH}_{2}$ group of amino acid.

\section{Discussion}

The study of radiolysis of hydrocarbon mixtures makes it possible to draw conclusions about the nature of the main radiation-chemical processes, their speed and the products formed. In radiolysis of limit hydrocarbons dehydrogenation occurs, secondary and tertiary C-C bonds are easily broken. And irradiation of unsaturated hydrocarbons leads to addition and polymerization reactions. The yield of polymerization products is increased. Exposure to ionizing radiation is accompanied by changes in the physical properties of fuels. Radioactive radiation occurs simultaneously. Polymerization leads to molecular weight increase and their cleavage. Cleavage always occurs because all organic substances are radiolysed to release gas [13]. One of the important characteristics of is viscosity and density, which are. Indirectly characterizes chemical properties. Fuel, fractional composition and paryaemost. They change the more, the greater the absorbed radiation dose.

Amount of the decayed hydrocarbon Increases with 
increase in total radiation doses. A large number of works on radiolysis of organic materials were published [14-16].

In saturated hydrocarbon radiolysis, the yields of some products are dose-independent, while yields of other products may increase or decrease as the dose increases. This is due to secondary reactions of unsaturated hydrocarbons accumulated by irradiation. Fuel stability is determined by the content of unstable products. The presence of unsaturated hydrocarbons in fuels causes the chemical non-stability of these products. Their evaporation into the atmosphere as reactive substances contributes to the formation of ozone, and their combustion products form toxic dienes. In fuels containing a large amount of non-essential hydrocarbons, the coxability is somewhat increased during storage and the color is degraded. One important characteristic of the fuel is viscosity and density, which indirectly characterize the chemical properties of the fuel, fractional composition, and vaporability.

\section{Conclusions}

In the conditions of our experiments at radiation of mixes of hydrocarbons (hexane-hexena) with various concentration (5, $10,20,40 \%$ ) on gamma source $\mathrm{Co}^{60}$ at the power of dose of $\mathrm{P}=0.10$ of $\mathrm{Gy} / \mathrm{s}$ in intervals of the absorbed doses $\mathrm{D}=34$ $103 \mathrm{kGy}$ at the room temperature the viscosity, density of mixes of hydrocarbons change. The viscosity and density change the more the absorbed radiation dose is. The amount of the decomposed hydrocarbon increases with the total irradiation dose. After radiation irradiation of hexane-hexene mixture (5\%) intensity of strips (2860-2960) (2975-2950) $\mathrm{cm}^{-1}$ - valence oscillations of $\mathrm{CH}_{3}$ are halved. At an absorbed dose of 288 hours (10\%) of the mixture 2140-1990 cm-1 -troy bonds appear. After irradiation for 288 hours, $40 \%$ of the hexane-hexene mixture dramatically decreases the absorption band of 1470-1435 cm-1 in alkanes. 1380-1370 cm-1deformation oscillations of $-\mathrm{CH}_{3} \mathrm{~g}$ and (2940-2915), (29752950) $\mathrm{cm}-1$ - oscillations of C-H bonds in alkanes decrease more than twice. The band of $1645-1640 \mathrm{~cm}^{-1}$. -valent fluctuations of $\mathrm{C}=\mathrm{C}$ bonds in alkenes is also significantly reduced. 2860-2960 $\mathrm{cm}^{-1}$ - valence oscillations $\mathrm{CH}_{3}$. 1645 1640 valence oscillations of $\mathrm{C}=\mathrm{C}$ in alkenes decrease, and 1800-1850- cm-1- deformation oscillations of C-H bonds in alkenes and substitution types at double bonds disappear. Processes after radiation develop for a long time after radiation termination, which leads to change of fuel composition. As a result of irradiation, the amount of unsaturated hydrocarbons increases among the products, and during storage the coxability is slightly increased and color is deteriorated.

\section{References}

[1] L. Y. Jabbarova, I. Mustafayev. «HIGH-TEMPERATURE RADIOLYSIS OF DIESEL FUEL» Journal of Applied Spectroscopy, Vol. 85, No. 4, 2018, Springer Science+Business Media, LLC p. 686-690.
[2] L. Y. Jabbarova, I. I. Mustafayev, S. Z. Malikova. "Influence of radiation on petroleum fuels". "International Journal of Applied and Fundamental Research", SIC "Academy of Natural History", Moscow, No. 7 (Part 2) 2017, p. 239-243.

[3] L. Y. Jabbarova, I. I. Mustafayev. Researches of Impact of Ionizing Radiation on Some Characteristics of Diesel Fuel. J. of Energy, Environmental \& Chemical Engineering. USA. Volume 2, Issue 4, August 2017, P. 41-45.

[4] I. I Mustafaev,. L. Y. Jabbarova, N. G Gulieva., R. S. Rzaev., and S. F. Alieva. "Effect of Ionizing Radiation on Lube Oil Fractions of Heavy Bituminous Oils." M.«High Energy Chemistry», 2014, Vol. 48, No. 5, p. 315-320.

[5] I. I. Mustafayev, L. Y. Jabbarova, Z. O. Nabizadeh, N. E. Ibadov. "Study of radiation-chemical transformation of synthetic oil from oil-bituminous rock". M. "High Energy Chemistry”, 2013, № 6, p. 449-455.

[6] I. I. Mustafaev, L. Y Jabbarova., N. Q., Gulieva K. M. Yagubov. "Radiation thermal refining of oil-bituminous rocks". Journal of Radioanalytical and Nuclear Chemistry. Budapest, Akademia Kiado, 2004, vol. 262, №2, P. 509-511.

[7] L. Y. Jabbarova, S. M. Aliev, S. Z. Melikova.”The impact of ionizig Radiation on Diezel fuel". Journal of Radiation Research. Volum 2, № 2, Baku, Azerbaijan, 2015, p. 71-7.

[8] L. Y. Jabbarova., I. I. Mustafaev, Z. O. Nabizade, R. S. Rzayev S. F. Akhmadbayova. "Radiation Chemical Conversion of Oil Derived from Oil-Bitumen Rock." Chemistry Journal of Moldova. General, Industrial and Ecological Chemistry. 2014, 9 (1), p. 80-84.

[9] L. Y. Jabbarova, N. E. Ibadov. "Alternativ Energy Sources". Azerbaijan Chemikal. Journal, №3, 2010, p. 128-132.

[10] I. I. Mustafaev., L. Y Jabbarova, N. G. Gulieva, K. M. Yagubov. "Radiation-thermal refining of organic parts of oilbituminous rocks". Radiation Safety Problems in the Caspian Region. Kluwer Academic Publishers. Printed in the Nethrlands. 2004, p. 141-146.

[11] L. Y. Jabbarova, I. Mustafayev. "Influence of a Radiation on Technical and Operational Qualities of Petrol". "Journal of Energy, Environmental \& Chemical Engineering." USA. Vol. 2, No. 4, 2017, p. 62-66.

[12] Tarasevich B. N. IR spectra of the main classes of organic compounds. Reference materials. M. 2012. p. 53.

[13] V. K. Milinchuk "Radiation resistance of organic materials": Handbook. M.: Energoatomizdat, 1986. P. 272.

[14] Ibadov N. A., Suleymanov B. A., Gurbanov M. A., Abdullayev E. T., Abbasova D. R. Radiolytic decomposition of polyaromatic carbohydrates//Energy and ecology. 2009. № 5 (73). Page 22-26.

[15] Ponomarev A. V., Civadze A. Y. Conversion of gas-like alkanes into liquid alkanes in case of electronic irradiation//Doc. Academies of Sciences. 2006. T. 411. No. 5. Page 652-658.

[16] Ponomarev A. V., Holodkova E. M., Ershov B. G. Electronbeam synthesis of fuel in the gas phase. Radiation Physics and Chemistry. 2012. V 81. I. 9. P. 1440-1444. 